\title{
ПАТОГЕНЕЗ И ПАТОГЕНЕТИЧЕСКИ ОБОСНОВАННАЯ ТЕРАПИЯ ХРОНИЧЕСКОГО ЭНДОМЕТРИТА
}

\section{И.С. СИДОРОВА \\ член-кор. РАМН, д.мед.н., просрессор кафедры акушерства и гинекологии факультета послевузовского профессионального образования врачей Первого Московского государственного медицинского университета им. И.М. Сеченова}

\section{И.О. МАКАРОВ}

д.мед.н., просрессор, зав. кафедрой акушерства и гинекологии факультета послевузовского профессионального образования врачей Первого Московского государственного медицинского университета им. И.М. Сеченова

\section{А.Л. УНАНЯН}

д.мед.Н., профессор кафедры акушерства и гинекологии факультета послевузовского профессионального образования врачей Первого Московского государственного медицинского университета им. И.М. Сеченова
$\mathrm{B}^{\mathrm{c}}$ структуре гинекологической патологии у женщин репродуктивного возраста значительное место занимает хронический эндометрит (ХЭ).

В настоящее время актуальность проблемы ХЭ приобретает не только медицинское, но и социальное значение, так как данное заболевание часто приводит к нарушению репродуктивной функции, являясь причиной бесплодия, неудачных попыток экстракорпорального оплодотворения, невынашивания беременности, осложненного течения беременности и родов.

Частота встречаемости ХЭ от общего числа биопсий эндометрия колеблется от 2 до $45 \%$. Широкие пределы изменения частоты ХЭ обусловлены низкой специфичностью и слабой чувствительностью клинических диагностических приемов, отсутствием четко выработанной концепции построения морфологического диагноза, что сопровождается часто встречающимися ложноположительными и ложноотрицательными результатами.

В настоящее время отсутствует единая концепция патогенеза ХЭ, раскрывающая механизмы формирования и взаимосвязи различных аспектов патогенетической цепи и детально объясняющая патологические основы хронического воспалительного процесса в эндометрии. В то же время понимание особенностей патогенеза ХЭ способствует проведению более адекватной, эффективной и научно обоснованной его терапии.

ХЭ наиболее полно соответствует определению хронического продуктивного интерстициального воспаления. При продуктивном воспалении сильно выражена стадия пролиферации (размножения) клеточных элементов, остальные стадии (альтерация и экссудация) не выражены. Среди видов продуктивного воспаления различают межуточное (интерстициальное) воспаление, гранулематозное, воспаление с образованием папиллом и кондилом и др. Межуточное воспаление характеризуется образованием клеточных инфильтратов в строме органов, которые по составу клеток могут быть полиморфно-клеточными инфильтратами, макрофрагальными, плазмоклеточными, гигантоклеточными и пр. Межуточное воспаление, как правило, имеет хроническое течение.

Отличительной особенностью механизма развития ХЭ является волнообразный и неуклонно прогрессирующий характер патологического процесса.

Необходимо отметить, что реакция воспаления - это универсальная защитная реакция организма на действие различных патогенных фракторов, благодаря которой происходит 
обезвреживание и уничтожение фракторов, вызвавших повреждение. При этом следует иметь в виду, что хроническое воспаление теряет свою биологическую сущность в качестве защитного процесса, так как утрачивается способность элиминации повреждающего агента и, соответственно, анатомо-фрункционального восстановления ткани.

Хроническому течению воспалительного процесса, кроме патогенных микроорганизмов, также способствует нарушение сложной цепи иммунокомпетентной системы и развитие аутоиммунных процессов, что чаще встречается при вирусной инфекции. Иммунная недостаточность является важным патогенетическим фактором, способствующим возникновению ХЭ, развивающегося на фроне дезадаптации иммунной системы, вторичного иммунного дефицита, снижающего сопротивление организма к инфекциям. Наиболее частыми клиническими проявлениями иммунодесрицитов являются смешанные, рецидивирующие, затяжные и тяжело протекающие инфрекции.

Один из важных аспектов патогенеза ХЭ нарушение ангиоархитектоники эндометрия. В частности, обнаружено склерозирование стенок сосудов и образование периваскулярного склероза вокруг спиральных артерий и в базальных отделах эндометрия, что приводит к развитию ишемии эндометрия.

Кровеносные сосуды при ХЭ умеренно полнокровные, стенки артерий мелкого калибра и артериол утолщены, часто просвет их сужен.

Нарушение микроциркуляции в свою очередь приводит к повышению коагуляционного потенциала крови. Повреждение сосудистой эндотелиальной поверхности (вследствие персистенции иноекции) является одной из основных причин нарушения продукции и соотношения простациклина и тромбоксана, результатом чего являются тромбозы.

В последнее время широко обсуждается вопрос о роли дисбаланса про- и антиоксидантной систем, а также влияния активных форм кислорода на развитие и прогрессирование хронического воспалительного процесса эндометрия. Между тем эти данные позволили бы приблизиться к решению проблемы эффрективной терапии при ХЭ.

Антиоксидантная система человека - это система, блокирующая образование высокоактивных свободных радикалов (активных форм кислорода). Продукция свободных радикалов, приводящая к окислению липидов клеточных мембран, является одним из наиболее мощных стимулов, повреждающих клетки и ткани при воспалительном процессе.

В нормальных физиологических условиях небольшое количество кислорода, потребляемого митохондриями, постоянно конвертируется в супероксид-анионы, перекись водорода и гидроксильные радикалы. Избыточная продукция этих радикалов является фактором повреждения, и на этот случай в клетке имеется естественная антиоксидантная система. Она представлена ферментами, среди которых важное значение имеют $\mathrm{Mn}^{2+}$ - и $\mathrm{Cu}^{2+}$-зависимые супероксиддисмутазы, глутатионпероксидаза, глутатионредуктаза и каталаза. Супероксиддисмутаза конвертирует супероксид-анионы в перекись водорода, которая затем трансформируется в воду другими фрерментами.

Активные фрормы кислорода химически очень агрессивны. Они повреждают белки и ДНК, а также вызывают перекисное окисление липидов - процесс, ведущий к тяжелому повреждению мембран клеток эндометрия.

Обращает на себя внимание фракт, что активность и уровень основных ферментов разрушения активных форм кислорода - супероксидисмутазы, каталазы и глутатионпероксидазы - в большинстве опухолей, а также в трансорормированных клетках снижены по сравнению с гомологичной нормальной тканью. Уже на ранних стадиях опухолевого роста в инициированных клетках существуют условия для поддержания более высокого уровня активных фрорм кислорода по сравнению с нормальными окружающими клетками, что является одним из факторов, определяющих избирательный рост инициированных клеток на определенных этапах промоции.

В настоящее время накопилось достаточно данных, свидетельствующих об участии радикальных окислительных реакций в клеточной пролиферации, опухолевой трансформации клеток и их запрограммированной гибели (апоптозе). Считается, что окислительный стресс средней интенсивности стимулирует пролифрерацию, в то время как многие антиоксиданты обладают выраженным антипролиферативным действием.

С указанных позиций очевидно, что стимуляция естественных антиоксидантных систем, привнесение экзогенных антиоксидантов один из необходимых моментов комплексной терапии ХЭ и профилактики опухолевой трансформации эндометрия при его хроническом воспалительном процессе.

Воспалительный процесс при ХЭ закономерно сочетается с типовыми расстройствами метаболизма. Венозная гиперемия в зоне хронического воспаления приводит к снижению напряжения кислорода (со 110 до 10-15 мм рт. ст.), что сопровождается подавлением активности метаболических реакций в клетках поврежденной ткани. Необходимо отметить, что нарушение обменных процессов не является только следствием дефицита кислорода. Так, в участках воспаления

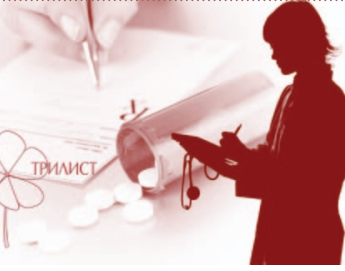

В настоящее время отсутствует единая концепция патогенеза ХЭ. Тем не менее установлено, что воспалительный процесс при этом заболевании сочетается с типовыми расстройствами метаболизма. Это в свою

очередь обусловливает необходимость использования метаболической коррекции в ходе лечения ХЭ 


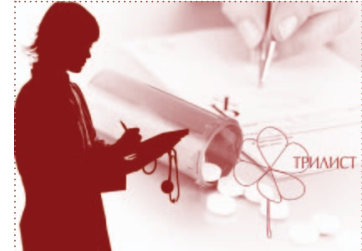

Одним из современных препаратов, который наиболее полно отвечает требованиям патогенетической терапии ХЭ, является актовегин Метаболическая терапия актовегином усиливает тканевой обмен, активирует энергетические процессь в клетках, устраняет последствия тканевой гипоксии происходят структурные изменения митохондрий клеток эндометрия, разобщение аэробного окисления и сопряженного с ним окислительного фоссфорилирования. При этом активируется гликолиз, накапливаются молочная, яблочная, янтарная, кетоглутаровая кислоты, недоокисленные продукты липолиза и протеолиза.

Наряду с повышением кислотности в зоне воспаления возрастает онкотическое и осмотическое давление в тканях. Это в определенной мере является результатом катаболических процессов - крупные молекулы расщепляются на более мелкие, их концентрация повышается. Нарастает деполимеризация белково-гликозаминогликановых комплексов, распад белков, жиров, углеводов и накопление продуктов распада: свободных аминокислот, уроновых кислот, аминосахаров, полипептидов, низкомолекулярных полисахаридов. Катаболические процессы затрагивают и соединительную ткань, что приводит к дезорганизации околокапиллярного соединительнотканного скелета, потенцируя расстройства микроциркуляции в зоне воспаления.

Повышение осмотического давления в очаге воспаления обусловлено выходом из поврежденных клеток ионов натрия, калия, кальция, макромолекулярных анионов, усиленной диссоциацией солей вследствие ацидоза ткани, а также нарушением выведения осмолярных веществ из очага воспаления на стадии венозной гиперемии и стаза.

Таким образом, реализация хронического воспалительного процесса эндометрия осуществляется на клеточном уровне в виде:

расстройства метаболизма;

s нарушения сложной цепи иммунокомпетентной системы и развития аутоиммунных процессов;

у ухудшения микроциркуляции;

д дисбаланса про- и антиоксидантной систем;

5 нарастающей гипоксии.

Исходя из выявленных механизмов развития, вовлеченных в возникновение и прогрессирование ХЭ, его эфрфективная терапия должна быть направлена на ключевые звенья патогенеза заболевания.

Одним из современных препаратов, наиболее полно отвечающим требованиям патогенетической обоснованной терапии ХЭ и оказывающим влияние на вышеуказанные звенья патогенеза, является актовегин.

Актовегин представляет собой депротеинизированный гемодериват высокой степени очистки, получаемый методом ультрафильтрации из крови молодых телят. Лекарственное средство содержит компоненты, обладающие высокой биологической активностью: аминокислоты, олигопептиды, нуклеозиды, олигоса- хариды и гликолипиды, фрерменты, электролиты и ряд важных макро- и микроэлементов.

Молекулярная масса органических соединений составляет менее 5000 Да. Актовегин содержит макроэлементы (магний, натрий, кальций, фросфрор), а также нейроактивные микроэлементы (кремний и медь). Макро- и микроэлементы, входящие в состав препарата, являются частью нейропептидов, ферментов и аминокислот, поэтому значительно лучше усваиваются, чем макро- и микроэлементы, находящиеся в составе солей. Одним из наиболее важных макроэлементов является магний основной компонент нейропептидных фрерментов и каталитический центр всех известных нейропептидов. Магний является компонентом 13 металлопротеинов и более 300 фрерментов в организме и необходим для синтеза клеточных пептидов. Микроэлементы, в частности медь, имеют большое значение для активности супероксиддисмутазы - одного из ключевых ферментов антиоксидантной защиты.

Супероксиддисмутаза способствует превращению супероксидного радикала в его электронейтральную форму $\mathrm{H}_{2} \mathrm{O}_{2}$ (перекись водорода). Кроме того, магний, который входит в состав глутатионпероксидазы, принимает участие в дальнейшем метаболизме $\mathrm{H}_{2} \mathrm{O}_{2}$, что приводит к образованию глутатиона.

Метаболическая терапия является ключевым компонентом комплексного лечения и направлена на усиление тканевого обмена, активацию энергетических процессов в клетках, устранение последствий гипоксии ткани, в т.ч. угнетение анаэробного гликолиза. С этой целью целесообразно использование актовегина, являющегося ярким представителем лекарственных средств с выраженным метаболическим действием.

Метаболические эфрфекты актовегина связаны с:

у усилением фризиологического процесса переноса кислорода и глюкозы в недостаточно снабжаемые ими ткани;

5 стимулированием активности фрерментов окислительного фоссрорилирования;

повышением обмена богатых энергией фоссфатов;

у ускорением, благодаря повышенному энергетическому обмену, распада лактата и $\beta$-гидроксибутирата, что способствует нормализации клеточной $\mathrm{pH}$.

Установлено, что клетки различного происхождения под влиянием актовегина увеличивают потребление глюкозы и улучшают утилизацию кислорода. Этот эффрект приводит к активации энергетических процессов внутри клеток и оказывает влияние на их функциональный метаболизм.

Особое место в структуре воспалительных заболеваний матки занимает послеродовой эндометрит, частота которого в общей 
популяции родильниц составляет от 2,6 до 7\%, а в структуре послеродовых гнойно-воспалительных заболеваний - более $40 \%$. Послеродовой эндометрит чаще всего протекает в легкой форме и заканчивается выздоровлением. Однако приблизительно в 1/4 наблюдений отмечается тяжелое течение данного осложнения, сопровождающееся гнойнорезорбтивной лихорадкой и возможностью генерализации инфекции.

Послеродовой эндометрит следует считать проявлением раневой инфекции, так как внутренняя поверхность матки после отделения последа представляет собой обширную раневую поверхность. Эпителизация и регенерация эндометрия заканчивается только через 5-6 нед после родов. Процесс восстановления эндометрия в послеродовом периоде представляет собой заживление раны, характеризующееся целым рядом гистологических особенностей.

Высокая распространенность абортов, а следовательно и их осложнений, приводит к существенному ухудшению репродуктивного здоровья женского населения. Аборт может привести к нарушению каждой из составляющих репродуктивного здоровья. При этом статистика по частоте абортов в нашей стране вызывает серьезную озабоченность. Известно, что аборт - это сильнейший стресс для женского организма. После любого, даже самого «удачного» аборта невозможно избежать отрицательных последствий - нарушается деятельность эндокринной, иммунной и нервной систем. Наибольшую опасность представляет инфицированный аборт, когда при распространении септической инфекции могут развиться сальпингоофорит, параметрит, метрит, тазовый перитонит, тромбофрлебит вен матки. Довольно распространенными последствиями являются задержка частей плодного яйца, истмико-цервикальная недостаточность, нарушение менструального цикла.

В настоящее время общеизвестно, что одним из наиболее частых осложнений аборта является воспаление слизистой оболочки матки, в т.ч. обострение уже имеющегося хронического воспалительного процесса. Необходимо отметить, что более чем у 50\% женщин, имевших в анамнезе воспалительные заболевания органов малого таза, после прерывания беременности происходит их обострение. Отдаленные осложнения аборта в виде хронических воспалительных процессов приводят к рубцово-спаечным изменениям внутреннего зева и шеечного канала, обусловливая формирование анатомической истмико-цервикальной недостаточности и, как следствие, невынашивание беременности.

Воспалительные осложнения могут возникнуть и после лечебных хирургических процедур, в частности раздельного лечебно-диагностического выскабливания полости матки, проводящегося с целью диагностики и лечения гиперпластических процессов эндометрия и дисфункциональных маточных кровотечений.

С учетом вышеописанных фракторов важной мерой профрилактики обострения хронического эндометрита и необходимой частью комплексной терапии послеабортного или послеродового ХЭ, а также после лечебно-диагностических выскабливаний матки является реабилитация структурнофрункционального состояния эндометрия, особенно при наличии факторов риска развития эндометрита.

Мы считаем, что использование актовегина у пациенток, прошедших процедуру хирургического аборта или диагно- стического выскабливания полости матки, с целью восстановления морфофрунццинального состояния ткани, а также профилактики постабортных и обострения хронических воспалительных процессов в эндометрии является научно обоснованным.

Примечательно, что помимо высокой терапевтической эффективности при различных заболеваниях актовегин демонстрирует хорошую переносимость и безопасность лечения, сравнимую с группой плацебо.

Таким образом, применение актовегина представляет значительный интерес для терапии ХЭ, в патогенезе которого задействованы механизмы нарушения метаболизма, гипоксии, ишемии и оксидативного стресса.

\section{ЛИТЕРАТУРА}

1. Краснопольский В.И., Серова О.Ф., Туманова В.А. и др. Влияние инфекций на репродуктивную систему женщин // Российский вестник акушерагинеколога. - 2004. - № 5.

2. Кузнецова А.В. Хронический эндометрит // Архив патологии. - 2000. № 3 (62). - С. 48-52.

3. Подзолкова Н.М., Бархина Т.Г., Осадчев В.Б. и др. Роль панорамной и микрогистероскопии в диагностике хронического эндометрита // Российский вестник акушера-гинеколога. - 2004. - № 6.

4. Шуршалина А.В., Ежова Л.С., Силантьева Е.С. Патогенетические подходы к терапии хронического эндометрита // Акушерство и гинекология. 2004. - № 6. - С. 54-56.

5. Шуршалина А.В., Дубницкая Л.В. Иммуномодулирующая терапия в программе реабилитации пациенток с хроническим эндометритом // Российский вестник акушера-гинеколога. - 2006. - № 1. - С. 36-38.

6. Buckley C.H., Fox H. Biopsy pathology of the endometrium. Arnold., 2002.

7. Eckert L.O., Hawes S.E. Endometritis: The clinical-pathologic syndrome. Am J Obstet Gynecol 2002; 186 (4): 690-5.

8. Eisert W.G. Dipiridamole // Platelets / Ed. by Michelson A.D. Cambridge (USA),2002. P. 215. Glasser S.R., Aplin J.D. The endometrium. Taylor and Francis., 2002.

9. Sharkey A.M., Smith S.K. The endometrium as a cause of implantation failure. Best Practice \& Research Clinical Obstetrics Gynecology. 2003; 17 (2): 289-307.

Статья впервые опубликована в журнале «Акушерство, гинекология и репродукция», 2010, № 3, С. 21-24.

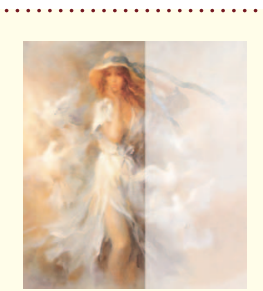

УВАЖАЕМЫЕ КОЛЛЕГИ!

Институт педиатрии, акушерства и гинекологии НАМН Украины

приглашает вас посетить школу-семинар «Гармония гормонов - основа здоровья женщины» в 2012 г.

16-17 марта - Школа климактерия

20-21 апреля - Школа эндокринной гинекологии «Гармония гормонов. Часть 2»

Заявки на участие присылайте на электронную почту ipag.gyn@gmail.com

Подробная информация представлена на сайте www.femina-health.com

Справки по тел.: 066-789-20-50 - Елена Николаевна Плужник 050-334-86-16 - Татьяна Васильевна Шевчук 097-472-19-28 - Людмила Вадимовна Калугина 